\title{
ESTADO AUTONÓMICO Y RESILIENCIA CONSTITUCIONAL. LAS SINGULARIDADES DEL ART. 155 CE Y LA EXPERIENCIA DE SU CONTROL
}

\section{State of the autonomous communities and constitutional resilience. The singularities of art. $155 \mathrm{CE}$ and the experience of its control}

\author{
FRANCISCO CAAMAÑO \\ Universidad de A Coruña \\ f.caamano@udc.gal
}

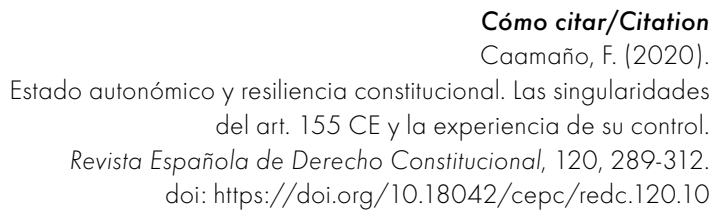

Resumen

En este trabajo se examina la naturaleza del poder excepcional de intervención previsto en el art. 155 de la Constitución Espańola desde la perspectiva de su control. A tal fin se diferencia entre el poder de coerción propio de un Estado federal y el establecido en la Constitución española. A partir de la consideración de que el control político también es un control constitucional, se defiende el carácter esencialmente político de ese poder excepcional de intervención, y, por tanto, la necesidad de que su control jurisdiccional se ajuste al mínimo imprescindible. Se sostiene, así, que el Tribunal Constitucional debe limitar su jurisdicción a constatar la necesidad y concurrencia del hecho habilitante y la constitucionalidad de las medidas aprobadas, sin examinar la necesidad o la proporcionalidad de estas. 


\title{
Palabras clave
}

Derecho excepcional; coerción federal; Estado autonómico; resiliencia constitucional; control político; autocontención judicial.

\begin{abstract}
This work examines the nature of the exceptional power of intervention regulated in art. 155 of the Spanish Constitution from the perspective of its control. To do this, a distinction is made between the coercive power of a federal state and that established in the Spanish Constitution. Starting from the consideration that political control is also a constitutional control, the essentially political character of this exceptional power of intervention is defended, and, therefore, the need for its jurisdictional control to be the minimum necessary. In this way, it is maintained that the Constitutional Court must limit its jurisdiction to establish the necessity and concurrence of the determining fact and the constitutionality of the approved measures, without examining the necessity or the proportionality of the same.
\end{abstract}

\section{Keywords}

Exceptional law; federal coercion; state of autonomous communities; constitutional resiliencie; political control; judicial self-restraint. 


\section{SUMARIO}

I. INTRODUCCIÓN. II. QUIEN CONTROLA LA APLICACIÓN DEL 155 CE... ¿̇ES EL SOBERANO?: 1. Controlar la decisión. 2. Controlar lo decidido: 2.1. El control parlamentario. 2.2. El control jurisdiccional. 2.3. El control contable. III. UNA REFLEXIÓN FINAL. BIBLIOGRAFÍA.

"If a man is on a plank in the deep sea which will only float one, and a stranger lays hold of it, he will thrust him off if he can. When the state finds itself in a similar position, it does the same thing."

Oliver Wendell Holmes

The Common Law, 1881

\section{INTRODUCCIÓN}

Es difícil examinar una constitución democrática y no ver en ella la fuerte influencia cultural y geográfica de ese entorno cargado de experiencias y principios que resumimos bajo la fórmula amplia del constitucionalismo. Pero una cosa es la transmisión de ideas, experiencias y técnicas constitucionales y otra, el corta y pega constitucional.

El art. $155 \mathrm{CE}$, como algún otro artículo que después de muchas vueltas solo ha aportado mayor perplejidad (me refiero al concepto de contenido esencial del art. 53.1 CE), pertenece a este segundo grupo. ¿Qué hacer ante la desobediencia grave de una comunidad autónoma, entidad pública de nueva creación, cuando no tenemos certeza sobre cuántas habrá, cómo serán (¿tendrán todas ellas un Gobierno parlamentario?), qué competencias asumirá cada una de ellas o por cuánto tiempo querrá ejercitarlas (principio dispositivo)?

En la traducción adaptada de la ley fundamental de Bonn — la misma en la que se hallaron las "fértiles» leyes marco- el constituyente de 1978 encontró la respuesta. Poco importaba que el Senado que se estaba diseńando nada tuviese que ver con el Bundesrat o que intelectual y culturalmente el federalismo en España fuese - y siga siendo- un perfecto desconocido que naufraga en un mar de naciones. Tampoco pareció oportuno preguntarse por qué conferir al Senado una intervención en asunto tan significado, cuando ninguna decisión políticamente trascendente se hace depender o, al menos, transitar por esa institución. La investidura y la moción de censura, la convalidación de decretos leyes o la declaración de los estados excepcionales (art. 116 CE) 
son patrimonio exclusivo del Congreso, que, además, dada su composición, actúa políticamente como Cámara de representación territorial.

Con todo, ha de reconocerse que este bicameralismo de papel resultaba sumamente útil para incorporar, desde el consenso, un poder constitucional tan delicado como el relativo al ejercicio de la coerción en defensa del Estado ante posibles incumplimientos graves por parte de los nuevos entes territoriales. Nada mejor para relajar el debate político sobre el significado profundo de una medida tan enérgica como la del art. $155 \mathrm{CE}$ que acudir, de una parte, al ejemplo alemán (traducción adaptada ${ }^{1}$ ) como fuente de legitimidad constitucional y, de otra, atribuirle la competencia al Senado: si no se atribuye al Congreso, entonces, no es importante.

Y, sin embargo, no es viable ni sostenible un Estado políticamente descentralizado (federal o no) sin el adecuado reconocimiento constitucional de la existencia de poderes de coerción en defensa del proyecto común para poder reaccionar frente a concretas acciones de uno o más entes descentralizados que pongan en peligro el pacto democrático plasmado en las normas. No hace falta recordar la Nullification Crisis a que dio lugar la decisión, de noviembre de 1832, de la Asamblea de Carolina del Sur al declarar nulas determinadas leyes federales tarifarias, y la respuesta contenida en la Force Bill ${ }^{2}$, ley por la que el

1 Resulta sumamente ilustrativo el debate habido en la Comisión de asuntos constitucionales y libertades públicas, celebrada 16 de junio de 1978, con ocasión del debate de las enmiendas presentadas al entonces art. 149 del Informe de la Ponencia sobre el Anteproyecto de Constitución. Ante la advertencia del Sr. Letamendía, al señalar que una «Comunidad Autónoma puede cumplir perfectamente las obligaciones que la Constitución u otras leyes le impongan, y, sin embargo, puede atentar gravemente al interés general de España, lo cual no se entiende», el Sr. Pérez Lorca tomó la palabra «para tratar de desvanecer las dudas que existen sobre la necesidad de este precepto", señalando que «es traducción casi literal de un precepto de la Constitución de la República Alemana». «Se trata, por tanto, del típico caso de intervención federal aprobada por el Senado [...] y estamos aquí precisamente dentro de un Estado que no se organiza como federal, introduciendo como garantía no la técnica de suspensión del acto o la intervención directa del Gobierno, que sería la propia de un Estado puramente autonómico, sino introduciendo para mayor garantía y seguridad de las Comunidades Autónomas una técnica típica del Estado federal y tomada, además, de un precepto de una Constitución federal moderna». Las citas pueden verse en Constitución Española. Trabajos Parlamentarios, Cortes Generales, Madrid, 1989, vol. II, p. 1682. Ni que decir tiene que la inclusión del «interés general», que, con razón preocupaba al diputado Letamendía, es genuinamente espańola y que no aparece en el art. 37 de la ley fundamental de Bonn.

2 Como habitualmente se designa a la An Act further to provide for the collection of duties on imports 4 Stat. 632 (1833), 22nd US Congress on March 2, 1833. 
Congreso de los Estados Unidos de América autorizaba al presidente Jackson el uso de la fuerza con el fin de hacer cumplir aquellas leyes, para comprender que nos encontramos ante una cuestión constitucionalmente crucial, a saber: cómo ordenar una situación de crisis de la constitución territorial desde la propia Constitución. Por tanto, lo que en ella se escriba o se deje de escribir, será clave para gestionar jurídica y políticamente un conflicto de esa naturaleza.

Mi tono crítico sobre la labor del constituyente en este punto obedece al propósito de eludir la respuesta fácil y reafirmar mi convicción sobre la inexistencia de casualidades inocentes. Sostener que el control de las potestades extraordinarias previstas en el art. $155 \mathrm{CE}$ se atribuyó al Senado por su condición de Cámara de representación territorial resulta demasiado ingenuo. Más bien, cabe intuir que se decidió no atribuírselo al Congreso porque esa facultad extraordinaria podía cuestionar gravemente el delicado e inestable consenso que se había armado en torno a la ordenación territorial del poder. Si el Gobierno y su mayoría parlamentaria están facultados a través del art. $155 \mathrm{CE}$ para intervenir una comunidad autónoma, entonces bien pudiera pensarse que el derecho a la autonomía política del art. 2 CE es un derecho "tutelado», sometido a la superior supervisión política de los órganos centrales del Estado, cuando, en puridad, aunque pudiese parecerlo, no era eso lo que realmente se perseguía. Antes bien, puesto que el Tribunal Constitucional se configuraba como el guardián jurídico de la Constitución, se encomendaba al Gobierno (con el Senado) la función de defensor político del Estado (entendiendo por tal la unidad de acción resultante de la suma de todos los niveles de gobierno democrático, jurídicamente articulados por la Constitución). El art. $155 \mathrm{CE}$ no fue ideado como una «sujeción/contención» del derecho a la autonomía, sino como un poder de defensa del Estado en su conjunto, incluido el sistema de autogobierno de sus entidades políticamente descentralizadas (Álvarez, 2016)

Comparto con él que lo que se protege mediante el art. 155 es el Estado en su conjunto o, en la formulación kelseniana, el «Estado total». Sin embargo, no creo que pueda proyectarse el concepto de lealtad federal (sea en su vertiente americana o germana) con un pretendido principio de lealtad al Estado autonómico. La lealtad federal es posible porque existe un pacto previo. En el Estado autonómico no se puede ejercer la coacción por incumplir los deberes de lealtad en relación con un pacto inexistente. Se ha intentado construir una versión autonómica del principio de lealtad federal, pero, a mi entender, es un intento condenado al fracaso, en la medida en que es el híbrido resultante de la combinación de dos conceptos distintos: la lealtad institucional y la lealtad a la Constitución. Ambos son principios indiscutibles en el funcionamiento de cualquier Estado (sea o no un Estado descentralizado). Pero la lealtad federal es una lealtad claramente distinta. Acaso, por ello, en el ámbito de la política —y no solo en él— nos 
El art. $155 \mathrm{CE}$ configura un poder excepcional que permite al Gobierno reaccionar frente a puntuales amenazas (y, en cierto modo, fracasos políticos) que pongan en riesgo nuestro proyecto de convivencia democrática. Es la «extraordinaria necesidad» (emulando la fórmula del art. 86.1 CE para el decreto ley) desencadenada por los actos de una comunidad autónoma que incumple la Constitución y las leyes o que atenta gravemente contra al interés general de España, el presupuesto habilitante de las potestades reconocidas en el art. 155 CE. Si el art. 116 CE busca un compromiso entre los derechos fundamentales y determinadas situaciones de emergencia, el art. $155 \mathrm{CE}$ habilita una cláusula de último recurso que concede transitoriamente poderes extraordinarios con el único fin de salvaguardar la conjunción que siempre debe existir entre Constitución y Estado.

Estado democrático y Constitución son realidades que mutuamente se necesitan. También, claro está, en los Estados políticamente descentralizados. Desde esta perspectiva el verdadero significado del art. $155 \mathrm{CE}$ no es tanto habilitar un poder extraordinario de coerción como constatar que no debe existir una relación preordenada y de prevalencia entre el Estado autonómico y su Constitución: el art. 155 CE es un meeting point en el que el Estado, como poder político, sale en defensa de la Constitución y en el que la Constitución habilita un procedimiento mediante el que se autoriza la salvaguarda política del Estado (quid pro quo).

El control del poder exorbitante a que puede conducir la activación de art. $155 \mathrm{CE}$, su debido manejo y comprensión, es la única oportunidad para procurar ese equilibrio y evitar los demoledores efectos secundarios de lo que Pedro Cruz calificó con acierto como «el exponente más agresivo y desafortunado de esa concepción de la unidad del Estado, latente en la formulación del artículo 2, como algo anterior, previo y por tanto superior a la Constitución misma» (1980). Y es que, en efecto, conviene no olvidar que el fundamento del Estado no es la unidad de la nación, sino la voluntad democrática de sus ciudadanos. Confundir la homogeneidad nacional con la defensa de la Constitución es no entender la Constitución de $1978^{4}$.

encontramos con invocaciones de la lealtad en el Estado autonómico que ocultan cierta insatisfacción con la descentralización política de la Constitución de 1978. Son leales defensores de la «unidad», pero no tan leales defensores de una Constitución que, guste o no, reconoce como derecho el autogobierno de nacionalidades y regiones.

4 Cuestión que fue el tema de fondo del conocidísimo debate entre Carl Schmitt - La defensa de la Constitución (Der Hüter der Verfassung, 1931) - y Hans Kelsen — «Quién debe ser el defensor de la Constitución?» ("Wer soll der Hüter der Verfassung sein?»), publicado poco después en Die Justiz-. Aunque no comparta algunas 
No estamos ante un poder jurídico de coerción estatal, sino ante un poder esencialmente político sujeto a ciertos condicionantes jurídico-constitucionales, a saber: que el actuar de la comunidad autónoma contrario al interés general no sea algo potencial (no es posible una aplicación preventiva del art. $155 \mathrm{CE}$ ), lo que explica que el trámite del "previo requerimiento» no sea mera cortesía institucional, y, en segundo lugar, que se produzca lo que podríamos denominar «un suplemento de motivación democrática» de las razones que mueven al Gobierno y que, en su caso, avalan las medidas que pretende adoptar, siendo el Senado el lugar elegido por el constituyente para ese cometido.

Pero, además, en el Estado autonómico ese poder de coerción se acompaña de una específica capacidad de resiliencia, en el sentido de que su constitución admite la posibilidad de «volver atrás» o, si se prefiere, de «regresar del salto» (ambas acepciones están incardinadas en la etimología del concepto), como solución adaptativa y transitoria mediante la que superar la situación adversa. Una suerte de ocasional devolution inversa en las potestades de ejecución que solo encuentra anclaje en la lógica estructural del principio de autonomía. El Estado autonómico, a diferencia del federal, tiene la capacidad de poder suplirse a sí mismo como mecanismo extraordinario de protección. La intervención a que se refiere el art. $155 \mathrm{CE}$ no disuelve ni suspende la autonomía, tampoco priva de eficacia jurídica a su derecho, ni sustituye la Administración autonómica por la estatal, pues ambas continúan conviviendo en el mismo territorio. Antes bien, el art. $155 \mathrm{CE}$ habilita al Gobierno para salir en defensa del principio de autonomía. Es más un mecanismo de autodefensa que de coerción. Su propósito consiste en aislar al gestor dañino y, al tiempo, garantizar la continuidad del Estado sin menoscabo de su legitimidad democrática. Un objetivo en absoluto fácil, pero no imposible.

Esta particularidad explica por qué, a diferencia de lo dispuesto en el art. 37 de la ley fundamental de Bonn, en nuestra Constitución se contemplan dos supuestos perfectamente diferenciados: el incumplimiento por la comunidad autónoma de las obligaciones impuestas por la Constitución y las leyes y atentar gravemente contra los intereses generales de España. Aunque pueda producirse, la Constitución no exige la concurrencia necesaria de ambos, y, de hecho, el segundo no siempre implica el primero 5 (en mi opinión, una proposición no de

de sus conclusiones, una interesante traslación de esa confrontación a la aplicación del art. 155 CE puede verse en Vilajosana (2019).

5 No lo entiende así en la STC 89/2019, de 2 julio. En este pronunciamiento el Tribunal desconoce la estructura conjuntiva de la frase para convertir su segunda opción (o atentar gravemente) en una subordinada de la primera: una "diferenciación que no debe entenderse como exclusión o contraposición entre ambos. El incumplimiento de 
ley declarando la independencia de un territorio del Estado no es un acto antijurídico y, sin embargo, en determinado contexto, puede ser perfectamente considerada como una actuación que atenta gravemente al interés general de España) ${ }^{6}$.

concretos deberes constitucionales o legales puede deparar, en según qué casos, lo que también pueda llegar a considerarse un grave atentado al interés general. Este último, a su vez, no habría nunca de denunciarse al margen del derecho. Es decir, como una cláusula general habilitante para la intervención discrecional en la autonomía, en la que, con arreglo a apreciaciones políticas o de mera oportunidad, se prescinda de constatar la infracción de la Constitución y las leyes, lo que no se compadecería ni con el principio del estado de derecho ni con la garantía constitucional de la autonomía (arts. 1.1 y 2 CE) que son "mandatos esenciales de nuestro ordenamiento constitucional"” (FJ 4 b). El Tribunal renuncia a diferenciar entre actos constitucionales, los jurídicos y políticos, lo que confirma su progresivo abandono del self-restraint. Un Estado derecho no es un Estado jurisdiccional. Si se analiza la primera comparecencia del entonces secretario de Estado para las Administraciones Territoriales, Bermúdez de Castro, ante la Comisión conjunta del Senado (Diario de Sesiones del Senado, núm. 202, 4-12-2017, p. 2 y ss.) tras la aprobación del acuerdo de intervención, se puede comprobar cómo, en su opinión, según los acuerdos del Gobierno y de Senado, «las medidas adoptadas en aplicación del artículo 155 perseguían cuatro objetivos. Además de la ya mencionada restauración de la legalidad constitucional y estatutaria, también pretendían asegurar la neutralidad institucional, mantener el bienestar social y recuperar el crecimiento económico y asegurar los derechos y libertades de todos los catalanes» (cit. en p. 3). Aunque enumera cinco, me interesa destacar que solo uno de ellos se refiere al incumplimiento de obligaciones jurídicas. Los cuatro objetivos restantes remiten a políticas públicas que afectan al interés general de la ciudadanía: «[...] la principal tarea que ha desarrollado el Gobierno de la nación en estas semanas ha sido normalizar la gestión política y administrativa de la Generalitat atendiendo a los problemas reales de los ciudadanos». Otro tanto puede decirse de las prioridades seguidas por el «administrador temporal» de la Generalitat, entre las que no figura el restablecimiento de la legalidad: «[...] han sido los servicios públicos, los pagos a proveedores, los pagos a los empleados públicos y los sectores más vulnerables de la sociedad catalana». No podía ser de otro modo, ya que antes de aprobarse el acuerdo las leyes y actos inconstitucionales ya había sido anulados o privados de eficacia jurídica.

6 Otro es el criterio del Tribunal Constitucional, que, abandonando sus precedentes, ha articulado una forzada argumentación para justificar la naturaleza jurídica de un acto inequívocamente político en la forma y en el fondo, como lo es una moción o una proposición no de ley. Así, frente a lo afirmado en el ATC 135/2004 («el simple enunciado de una proposición contraria a la Constitución no constituye objeto de enjuiciamiento de este Tribunal»), a partir de las SSTC 42/2014 y 259/2015 se sostendrá que «en determinados supuestos los actos parlamentarios no legislativos tienen una eficacia que va más allá de la mera expresión de un juicio, deseo o aspiración, siendo susceptibles de efectos jurídicos». 
No puede obviarse que la fórmula utilizada en el apartado segundo del art. $155 \mathrm{CE}$ aminora y, en cierto modo, administrativiza el poder previsto en su párrafo primero, lo que ha dado lugar a un interesantísimo y fructífero debate académico. Ahora bien, con independencia del alcance jurídico que se le quiera dar, el intérprete ha de ofrecer una respuesta razonable a la siguiente pregunta: ¿qué hacer si las «instrucciones» del Gobierno no son cumplidas por la comunidad autónoma a la que van destinadas?

Sería absurdo sostener que se trata de una cuestión sin respuesta constitucional, porque entonces absurdo sería el art. $155 \mathrm{CE}$. Tampoco cabe acudir al remedio del control jurisdiccional, pues, si se ha activado el art. $155 \mathrm{CE}$, será, entre otras razones, porque la vía judicial ha resultado insuficiente, estéril o inadecuada para afrontar la crisis y reponer la normalidad constitucional.

En esa tesitura solo cabe entender que la palabra instrucciones es un genérico mediante el que referirse formalmente a la ejecución de unas "medidas» que, en principio, no están constitucionalmente tasadas y que, por tanto, cumplido el presupuesto habilitante del art. 155.1 CE, variarán en función del hecho y la intensidad política de la situación ante la que se reacciona, correspondiendo al Gobierno y al Senado valorar sus circunstancias y determinar los medios más adecuados de actuación 7 . Una decisión que, a mi juicio, es esencialmente política, lo que no significa que esté exenta de todo control.

\section{QUIEN CONTROLA LA APLICACIÓN DEL ART. 155 CE... ¿ES EL SOBERANO?}

El control de los poderes atribuidos al Gobierno para intervenir una comunidad autónoma se convierte, de este modo, en el corazón del asunto. La singular capacidad de resiliencia que caracteriza a la constitución del Estado autonómico me lleva a considerar que soberano no es quien «decide acerca del artículo 155", como nos decía Pedro Cruz (1980) para advertirnos de sus muchos riesgos, sino aquel o aquellos que responden de su control ${ }^{8}$. El art. $155 \mathrm{CE}$ será

7 En este sentido, en la STC 89/2019 (FJ 10 a) se declara que tampoco cabe la equiparación entre las "medidas necesarias» para el restablecimiento del orden jurídico conculcado (art. 155.1 CE) y las «instrucciones» que a efectos de su «ejecución» pueda el Gobierno dirigir a las autoridades autonómicas (art. 155.2 CE). Por la misma razón, el art. 155.1 CE «tampoco exige que las medidas aprobadas por el Senado hayan de ser necesariamente autoaplicativas».

8 Por eso me parece muy poco afortunado sostener que el art. $155 \mathrm{CE}$ «determina que el Estado, como una consecuencia del principio de unidad y de la supremacía 
lo que sus controladores quieran. Pero ¿quiénes son o han de ser esos controladores?, ¿`cómo distribuir sus cometidos?

La asignación y, en su caso, el reparto de identidades dependerán en muy buena medida de la naturaleza que asignemos al poder excepcional del art. $155 \mathrm{CE}$. Si consideramos que es un poder esencialmente político y que, por tanto, descansa en razones de oportunidad, su control también ha de serlo. Por el contrario, si acentuamos la vertiente jurídica de ese poder y somos partidarios de su máxima objetivación y predeterminación, entonces su control habrá de ser preferentemente jurídico.

Para adentrarme en este delicado territorio era necesario, en primer lugar, dejar claro mi punto de partida. Espero haberlo conseguido en la introducción: considero que el art. $155 \mathrm{CE}$ confiere un poder constitucional esencialmente político, lo que no es óbice para que su ejercicio esté sujeto a ciertas reglas de derecho, comenzando por las impuestas en la Constitución.

En segundo lugar, adelanto que mi análisis se articulará en torno a una elemental metodología consistente en diferenciar entre «el control de la decisión» y el "control de lo decidido", ya que una cosa es fiscalizar la propuesta y el acuerdo de aprobación de las medidas de intervención y otra, bien distinta,

del interés de la Nación, quede colocado en una posición de superioridad en relación a las comunidades autónomas» (STC 89/2019, FJ 4 a). Como se sabe, las CC. AA. también son Estado y el interés general que protege el art. 155 CE no es el de sus órganos centrales sino el del Estado autonómico en su conjunto. El principio de unidad no coloca a los órganos generales del Estado en una posición de superioridad (y menos al Gobierno y al Senado, omitiendo el rol central de Congreso de los Diputados), ni parece razonable inferir del art. 155 CE un principio de sumisión por completo ajeno a la estructura territorial del Estado basado en el principio de competencia. El objetivo principal del art. 155 no es proteger la Constitución ni la unidad del ordenamiento (para eso ya están el Poder Judicial y el Tribunal Constitucional), sino al Estado que la Constitución configura y limita. En todo caso, la afirmación transcrita entra parcialmente en contradicción con el recordatorio de doctrina que se hace en el apartado siguiente del mismo fundamento jurídico: «Gobierno y Senado son aquí llamados por la Constitución a actuar como garantes del "ordenamiento integral del Estado" (SSTC 99/1986, de 11 de julio, FJ 8, y 137/1986, de 6 de noviembre, FJ 3) o de la "totalidad de la organización jurídico-política de la Nación española, incluyendo las organizaciones propias de las nacionalidades y regiones que la integran y la de otros entes territoriales dotados de un grado inferior de autonomía" (STC 32/1981, de 28 de julio, FJ 5)». Cierto es que, a continuación, se reafirma la existencia de esa «situación de supremacía» ex art. 155 CE. 
verificar la pertinencia y licitud de los actos y resoluciones dictados en virtud de aquellas.

Y, por último, aunque sea un clásico recurrente, conviene recordar la diferencia conceptual entre uno tipo y otro de control para evitar equívocos, toda vez que es una cuestión que dista de ser pacífica. Siguiendo a Manuel Aragón (1995: 91), mientras un control jurídico se caracteriza por su objetividad (preexistencia de un canon de enjuiciamiento no disponible por el controlador), por fundamentarse en razones jurídicas, por su carácter necesario (el control ha de ser ejercido y su resultado, ejecutado), y por atribuirse a órganos imparciales dotados de especial conocimiento técnico, el control político es un control subjetivo, de oportunidad, de carácter voluntario (no existe la puntual obligación de controlar ni de ejecutar la decisión resultante del control) y realizado por órganos políticos. Ahora bien, este deslinde de poco sirve si se utiliza desde la creencia de que la regulación por el derecho de cualquier actividad política la convierte automáticamente en una actividad jurídica, pues no cabe confundir la regulación jurídica de fenómenos políticos con la sustitución de su naturaleza. Por estar regulada, la política no deja de ser política, y tratarla como si fuese una realidad jurídica solo sirve para debilitar la autoridad del derecho.

\section{CONTROLAR LA DECISIÓN}

La decisión corresponde al Gobierno. Solo este órgano constitucional puede valorar la situación y activar el art. $155 \mathrm{CE}$. Nadie puede ocupar su lugar. Y esa valoración es, fundamentalmente, política. El impacto de los incumplimientos de la comunidad autónoma, su eventual afectación al interés general y la determinación de su gravedad son estimaciones subjetivas y de oportunidad, es decir, estimaciones políticas. La Constitución solo establece dos condiciones de procedibilidad. Todo lo fía al buen criterio del Gobierno y del Senado: suya es la decisión y suya, la responsabilidad. En último término, será el pueblo español el que juzgue si han acertado o se han equivocado y, en esa tarea de accountability democrática, las razones jurídicas serán previsiblemente secundarias. El Gobierno y el Senado deciden, conscientes de que el pueblo tendrá la última palabra.

Acaso por ello, en la República Federal Alemana, el Bundesverfassungsgericht solo fiscaliza la concurrencia del presupuesto habilitante, de modo que las medidas de ejecución forzosa únicamente están sujetas a control político. Parece que, al Tribunal Constitucional Federal alemán, cuando se activan poderes de naturaleza política que la Constitución atribuye específicamente a 
otros órganos constitucionales, no le preocupa tanto como al español que existan espacios de decisión constitucional ajenos a su jurisdicción? 9 Y es que la preocupación debiera ser otra, a saber: que, en un asunto de profunda trascendencia política, el art. $155 \mathrm{CE}$ no convierta al Tribunal en un sustituto impropio de la expresión democrática del pueblo.

¿Qué habría ocurrido si el Tribunal Constitucional español hubiese concluido - como, entre nosotros, defiende un importante sector de la doctrina ${ }^{10}$ - que la facultad de disolución del Parlamento incluida en el acuerdo del Senado no forma parte de las medidas constitucionalmente permitidas por el art. $155 \mathrm{CE}$, declarando, en consecuencia, su inconstitucionalidad? Previsiblemente, se produciría un conflicto sobre el conflicto, con más frentes y nuevos actores.

Cuando se trata de resolver un asunto encendido, de inequívoca naturaleza política, que previamente ya ha desbordado los límites razonables de la sujeción ordinaria al derecho y en el que el reproche no es tanto una infracción de la Constitución cuanto la profunda deslealtad de unos gestores políticos que, pervirtiendo su estatus y marco institucional, actúan contra el Estado democrático que se lo ha concedido, los argumentos jurídicos semejan adornos de otras razones.

La alegalidad, las lagunas normativas, la intención, las omisiones, las vías de hecho y el delicado deslinde entre la libertad ideológica y lo que no lo es son espacios en los que deliberada y peligrosamente se confunde la lucha por la justicia con la lucha por el derecho. Territorios cuyos dirigentes rehúyen la normatividad o la reutilizan a conveniencia creando nuevos códigos - derecho a decidir, consultas populares no refrendarias, elecciones plebiscitarias...-, nuevos significantes cargados de apariencia (Caamaño, 2017: 6). No son, ni pueden ser, territorios sin ley, pero, en ellos, la garantía jurisdiccional de la Constitución resulta a veces inadecuada y siempre insuficiente. Se requieren altas dosis de política democrática que ninguna sentencia puede sustituir.

El control de constitucionalidad del art. $155 \mathrm{CE}$ debe alejarse de todo indicio de activismo judicial y dejar un amplio espacio a la decisión discrecional de los órganos constitucionales a los que se encomienda la tarea de apreciar los presupuestos y proponer las medidas de intervención, respetando el minimalismo de su regulación constitucional. No basta la prudencia. Es necesario explicar las razones que aconsejan el self-restraint: la procedencia o

\footnotetext{
9 Véase la STC 89/2029, FJ 2 c), in fine.

10 Véanse, entre otros, García de Enterría (1983: 184), García Torres (1984: 1283), Albertí Rovira (2018) y Urías (2019: 111).
} 
no de la intervención y el contenido de las medidas que se propongan es asunto que la Constitución reserva al control político del Senado.

Esto implica que el acuerdo del Consejo de Ministros declarando la activación del mecanismo excepcional del art. $155 \mathrm{CE}$ no pueda ser sometido a control jurisdiccional (ni ante el Tribunal Constitucional ni ante la jurisdicción contencioso-administrativa), ni siquiera en sus elementos reglados, cuya verificación corresponde, en su caso, a la Mesa del Senado, como consecuencia de la calificación y admisión a trámite de la iniciativa.

En este sentido, resulta de sumo interés el Auto 11878/2017 de la Sección Cuarta de la Sala Tercera del Tribunal Supremo, de 15 de diciembre de 2017, en el que, frente al recurso promovido por la Generalitat de Cataluña contra el Acuerdo del Consejo de Ministros de 21 de octubre de 2017, se declaró:

El acto impugnado no ha sido dictado en el ejercicio de una actuación administrativa que pueda ser controlada por los Tribunales de este orden contencioso-administrativo y se encuentra fuera del ámbito de control que nos reserva el artículo 106.1 de la Constitución y más allá de los límites de conocimiento que nos asignan los artículos 1 y 2 de la LJCA, por lo que carecemos de jurisdicción para enjuiciarlo [...], nos encontramos aquí ante un procedimiento constitucional que se dirige al Senado y que no produce efectos «ad extra».

Lo que se impugna es el acto de iniciación o de impulso parlamentario del procedimiento del artículo $155 \mathrm{CE}$ ante la Cámara Alta. El Senado se vincula por él a actuar (conforme al artículo 189.1 y 2 de su Reglamento) por lo que, como acto de iniciación ("saisissement»), se subsume entre los procedimientos parlamentarios, de los que no nos corresponde conocer (Conf., a contrario, el artículo 1.3 a) LJCA) [...], además, que una vez que la Cámara asume la actuación impugnada en este tipo de actos la misma ostenta ya fuerza de ley o valor de ley y tampoco puede encuadrarse dentro del ámbito de conocimiento que para este orden contencioso-administrativo definen los artículos 1 y 2 de la LJCA (razonamiento jurídico 4. ${ }^{\circ}$ ).

En efecto, se trata de un acuerdo cuya principal finalidad es iniciar un procedimiento excepcional de relación entre el Gobierno y el Senado todavía carente, como se dice en el citado auto, de eficacia jurídica ad extra, por lo que, aunque se trate de un acto dictado por el Gobierno en su condición de órgano constitucional (y no de órgano superior de la Administración del Estado) ${ }^{11}$, tampoco puede ser impugnado ante el Tribunal Constitucional.

11 Véase, al respecto, STC 83/2016, de 28 de abril (FJ 10). 
Estamos ante un procedimiento integrado en el que, a mi juicio, solo es susceptible de recurso el acuerdo final que, en su caso, adopte el Senado.

Cabe plantearse qué ocurriría si la Mesa del Senado inadmitiese a trámite el escrito gubernamental. Es obvio que por la condición del sujeto proponente ni podría formularse recurso de reconsideración ante la Mesa ni, en último término, plantearse un recurso de amparo por vulneración de los derechos fundamentales del art. $23 \mathrm{CE}$. Tampoco parece posible que el Gobierno pueda interponer un conflicto entre órganos constitucionales ex art. 73 y ss. de la LOTC. Sin embargo, la Mesa, en su función de calificación, no debe sustraer al pleno de la Cámara un debate de tanta relevancia política. Por ello, ante una inadmisión que se fundamentase en criterios de oportunidad o que no permitiese la eventual subsanación del escrito remitido por el Gobierno, cabría pensar, como última alternativa, en la posibilidad de que un diputado o un grupo parlamentario promoviesen un amparo del art. 42 LOTC, al haber impedido indebidamente la Mesa de la Cámara el ejercicio de su derecho a representar ex art. $23 \mathrm{CE}$.

El control que corresponde al Senado está regulado en la Constitución (exigencia de mayoría absoluta) y en el Reglamento de la Cámara. Todo debate político puede incorporar argumentos jurídicos, pero no olvidemos que, en principio, los actos parlamentarios no tienen que ser motivados. Por tanto, el Gobierno defenderá sus razones y propuestas y el Senado, conforme al art. 189 del Reglamento, los compartirá, los modificará o denegará su apoyo, en cuyo caso todos los actos y decisiones previos habrán de considerarse como interna corporis acta y, por tanto, no susceptibles de control jurisdiccional. No cuestiono que el acuerdo del Senado, una vez aprobado, tenga fuerza de ley, como bien se razona en las SSTC 89/2019 y 90/2019. Antes bien, lo que quiero decir es que si no se alcanza la mayoría absoluta constitucionalmente requerida no existe acuerdo y, por tanto, el voto negativo del Senado no es una decisión susceptible de control jurisdiccional. En suma, ni el acuerdo del Gobierno ni la votación en contra del Senado tienen más control que el estrictamente político.

Como Cámara parlamentaria, la regla general ha de ser que el Senado no motiva, vota. Sin embargo, el art. 189.4 de su Reglamento exige que la Comisión General de las Comunidades Autónomas, o la comisión conjunta que se constituya para examinar y debatir el escrito remitido por el Ejecutivo ${ }^{12}$, formule «una propuesta razonada sobre si procede o no la aprobación solicitada

12 Véase el Acuerdo de la Mesa del Senado de 21 de octubre de 2017 (Boletín de las Cortes Generales, Senado, núm. 162, p. 72), en cuyo apartado segundo se constituye, al amparo de lo dispuesto en los arts. 189.2 y 58 del Reglamento del Senado, una 
por el del Gobierno, con los condicionamientos o modificaciones que, en su caso, sean pertinentes».

Estaríamos, pues, ante una excepción, toda vez que la "propuesta razonada» que la Comisión remite al Pleno ha de llevar incorporadas las "razones» por las que el Senado habría considerado procedente la intervención solicitada. Repárese en que la justificación se exige únicamente para apreciar la concurrencia del presupuesto habilitante y no respecto de las concretas medidas de intervención acordadas. En efecto, según el art. 155.1 CE, a quien corresponde «aprobar las medidas necesarias» es al Gobierno, mientras que lo que se demanda del Senado es que apruebe (compruebe) la necesidad de adoptarlas, pero no la idoneidad y pertinencia de cada una de las medidas propuestas, que solo puede "condicionar o modificar» (art. 189.4 RS). A la vista de ello, parece claro que el Senado no puede in novar, incluyendo medidas nuevas o sustituyendo las comunicadas por otras alternativas. Solo puede trabajar sobre las propuestas. La duda surge a la hora de determinar si la palabra condicionamiento que utiliza el citado precepto constitucional comprende la posibilidad de supresión, pues, en tal caso, el Senado estaría declarando de forma indirecta lo innecesario de la medida, lo que supondría ampliar su ámbito material de control ${ }^{13}$.

En todo caso, esta y otras incertidumbres similares que pueden plantearse en función de la naturaleza y redacción del acuerdo gubernamental deben ser, a mi juicio, objeto de discusión en los órganos parlamentarios correspondientes

Comisión conjunta de las comisiones General de las Comunidades Autónomas y Constitucional integrada por 27 miembros.

13 A nadie se le oculta que, en este punto, los esfuerzos de deslinde teórico solo juegan un papel puramente orientativo. En la práctica parlamentaria se puede «adicionar» modificando y «suprimir» condicionando una medida hasta hacerla inoperante. Ello significa que es del todo imposible limitar la potestad decisoria del Senado a la mera aprobación, o no, del acuerdo remitido por el Consejo de Ministros. Desde el momento en que el Senado puede "condicionar o modificar», y, en muchos casos, de ello dependerá que existan mayorías para la aprobación o no de la propuesta, es inevitable impedir su capacidad creativa. Solo un Gobierno con mayoría absoluta en el Senado podría asegurarse que su propuesta no será alterada. En todo caso, la reflexión teórica sobre esta cuestión sí puede resultar muy útil para deslindar qué aspectos pueden ser susceptibles de control ante el Tribunal Constitucional. De hecho, en la STC 90/2019, FJ 1, al identificar el objeto del recurso se reconoce con naturalidad que «[e]l acuerdo del Pleno del Senado hace suyas, con ciertas modificaciones, supresiones y adiciones, las medidas sometidas a la aprobación del Senado por el acuerdo del Consejo de Ministros», sin que se considere que esas "supresiones y adiciones» puedan exceder el margen de actuación autorizado por el art. 155.1 CE. 
y no por el Tribunal Constitucional. Cuando uno examina el recurso de inconstitucionalidad interpuesto por la Generalitat de Cataluńa y algunos de los votos particulares presentados a la propuesta aprobada por la comisión conjunta, comprueba una notoria coincidencia argumental. Al Tribunal Constitucional no le corresponde explicar en sus sentencias por qué el rechazo político de esos votos particulares estaba constitucionalmente justificado. Antes bien, debe limitar su enjuiciamiento a lo estricta e inequívocamente constitucional, dejando que el Senado, a través de sus órganos internos, resuelva esas dudas interpretativas que no afectan directamente al núcleo duro del art. 155 CE.

Es de desear que el art. $155 \mathrm{CE}$ no tenga que volver a activarse. Pero si se diese el caso, lo que ocurra en el Senado dependerá del supuesto fáctico que justifique la iniciativa, de la intensidad de la propuesta gubernamental y de la composición política de la Cámara. Ningún Gobierno, aunque tenga la mayoría absoluta, querrá ejercer la coerción sobre una o varias CC. AA. si no cuenta con el apoyo de otras fuerzas políticas, y, a veces, para obtenerlo será necesario negociar en sede parlamentaria. No duden de que si para alcanzar el acuerdo han de admitirse medidas inicialmente no previstas en el acuerdo gubernamental o suprimirse alguna de las allí propuestas así se hará y que, muy probablemente, el primero en promoverlas será el grupo parlamentario que sustente al Gobierno. Pues bien, si el Tribunal Constitucional, a partir de la realidad de un caso concreto, va más allá de lo constitucionalmente imprescindible, asentando una doctrina constitucional muy densa, se corre el riesgo de imponer una rigidez interpretativa que asfixie la necesaria flexibilidad y capacidad de creación que es propia de los órganos parlamentarios.

Tomemos el único ejemplo que nos suministra la experiencia ${ }^{14}$. En el Acuerdo del Senado de 27 de octubre de 2019, la concurrencia del presupuesto habilitante se justifica del modo siguiente: «El Senado constata: a) La extraordinaria gravedad en el incumplimiento de las obligaciones constitucionales y la realización de actuaciones gravemente contrarias al interés general por parte de las Instituciones de la Generalitat de Cataluña». Ni se mencionan los incumplimientos, ni cuáles han sido las actuaciones contrarias a los intereses generales, ni los motivos de la extraordinaria gravedad. Tampoco se afirma que el Senado hace suyos los argumentos previamente manifestados por el Gobierno.

14 Una ordenación sistemática y muy detallada tanto de las fuentes directas como de las principales resoluciones y manifestaciones jurídicas habidas como consecuencia de esta primera aplicación del art. $155 \mathrm{CE}$, así como una completa bibliografía sobre el asunto, puede verse en el utilísimo trabajo de Martín i Alonso (2019). 
El Senado no razona; como bien se dice en el acuerdo, constata. El acuerdo es, en este punto, reproducción fiel de la propuesta elaborada por la comisión conjunta sobre la que pesa la obligación, ex art. 189.4 del Reglamento del Senado, de formular una "propuesta razonada».

En la STC 89/2019, después de afirmarse que «[e]l Senado debe controlar tanto estas condiciones previas (se refiere al requerimiento y su contestación) como también la verificación del presupuesto habilitante que fija el mismo art. 155.1 CE» (FJ 5), no se dedica ni una sola línea a analizar si el acuerdo objeto de impugnación razona suficientemente ese segundo aspecto ${ }^{15}$. Fijémonos en las palabras. El acuerdo del Senado emplea el verbo constatar y el Tribunal Constitucional opta por verificar. Ambos son coherentes con la naturaleza política del control encomendado al Senado. El Senado "constata» o «verifica». Así entendido, el Senado no tiene por qué explicar en el acuerdo los motivos por los que se considera cumplido el presupuesto habilitante del art. $155 \mathrm{CE}$. Por tratarse de un órgano político, su cometido se circunscribe a constatarlo, a verificarlo. En coherencia con ello el Tribunal Constitucional debería limitar su enjuiciamiento a examinar si esa constatación o verificación se ha efectivamente producido, sin juzgar cuáles fueron los motivos por los que el Senado lo constató. Además, podría alegarse que la "propuesta razonada» del art. 189.4 del Reglamento del Senado no puede interpretarse como una obligación de la comisión conjunta de motivar la concurrencia del presupuesto habilitante, sino de la "procedencia» a efectos políticos de que el Pleno apruebe la solicitud del Gobierno ${ }^{16}$.

15 Probablemente se deba al hecho de que el Tribunal examina la concurrencia del presupuesto habilitante al analizar el requisito del previo requerimiento en el FJ 6 de la STC 89/2019, a pesar de que en el FJ 2 a) se había declarado: «Lo cuestionado en este recurso es, por tanto, el acuerdo que contiene el conjunto de medidas en los términos en los que fueron aprobadas por el Senado». Es irrelevante a estos efectos que tal acto parlamentario se formalizara incorporando o «confirmando su cumplimiento por lo que lo presupone después». Sin embargo, la sentencia parece presumir que el Senado ha hecho suya la argumentación del Gobierno sobre las razones que justifican el cumplimiento del presupuesto habilitante del art. $155 \mathrm{CE}$, cuando, si así fuese, esa argumentación debería figurar en el acuerdo o, al menos, remitirse a ella de forma expresa.

16 Según creo, la utilización de art. 155 CE y la determinación de las medidas de intervención forman parte de la esfera de discrecionalidad del Gobierno, por lo que el Senado no podría, a mi juicio, introducir cambios que desnaturalizasen o vaciasen de contenido la propuesta gubernamental. Desde una perspectiva práctica la cuestión puede tener importantes consecuencias. En efecto, cabe preguntarse si un Gobierno que carece de una mayoría de apoyo en el Senado y ve cómo en la comisión se altera 
Ahora bien, esta interpretación a favor del predominio del control político del poder de coerción habilitado por el art. $155 \mathrm{CE}$ resulta, en mi opinión, excesiva, porque reduce la garantía jurídica de su control jurisdiccional a los requisitos de procedibilidad establecidos en dicho precepto, lo que posibilitaría un uso inadecuado o exorbitante.

El Tribunal es consciente de ello. Por un lado, ha de delimitar el ámbito de su jurisdicción y, por otro, respetar la naturaleza política del control constitucionalmente asignado al Gobierno y al Senado. Aunque, en mi criterio, la STC 89/2019 debiera haber explicado desde un principio las razones constitucionales que justifican el selft-restraint del Tribunal (en vez de justificar una pretendida universalidad de su jurisdicción), cuando se entra más en detalle ha de reconocerse que tiene muy presente la naturaleza esencialmente política del poder que el art. $155 \mathrm{CE}$ confiere transitoriamente al Gobierno y su amplio margen de discrecionalidad.

En el FJ 11 de la mencionada sentencia, al justificar por qué la «necesidad» de las medidas que materializan la intervención no implica que, además, tengan que ser proporcionadas, se advierte de lo siguiente:

La aplicación de lo que se denomina «medio más benigno o menos gravoso» no puede ser empleado por esta jurisdicción en este caso. No ha de decirse otra cosa a propósito del llamado criterio de "gradualidad", sugerido por las representaciones procesales de la Generalitat de Cataluña, porque es ese mismo criterio formulado de otro modo. De aceptar tales criterios, el Tribunal ocuparía el lugar

su propuesta en contra de su voluntad puede retirar su iniciativa, o si, por el contrario, una vez registrada en la Cámara, esta la asume como propia. Decantarse por una u otra opción supone elegir entre una capacidad constitucional compartida Gobierno-Senado y una facultad exclusivamente gubernamental cuyo ejercicio requiere superar el trámite de la mayoría absoluta del Senado ¿Quién es el dueño de la iniciativa? Parece que un Gobierno nunca debiera verse obligado a ejecutar medidas de las que discrepa, por lo que me inclino por la primera solución. En todo caso, y dependiendo de la composición del Senado, sería posible que el presidente del Gobierno disolviese la Cámara e intentase aprobar su propuesta en la Diputación Permanente, lo que nos lleva a la delicada cuestión de saber si puede activarse el art. $155 \mathrm{CE}$ hallándose disuelto el Senado y si, en relación con el art. $155 \mathrm{CE}$, dado su carácter excepcional, la Diputación Permanente puede sustituir al Pleno. A estos efectos, no creo que pueda establecerse un paralelismo entre los supuestos excepcionales del art. $116 \mathrm{CE}$ y el previsto en el art. $155 \mathrm{CE}$, pues, mientras en el primer caso la autorización o prórroga otorgada por el Congreso no produce un efecto regulatorio directo, ya que se requiere del ulterior real decreto aprobado por el Consejo de Ministros, no ocurre lo mismo con el acuerdo del Senado ex art. $155 \mathrm{CE}$. 
que la Constitución ha reservado en este procedimiento al Gobierno, para la propuesta, y al Senado, para la decisión final. Ambos deben realizar un determinado juicio de necesidad sobre las medidas que procedan, valoración que puede llegar a ser enjuiciada por este Tribunal, si bien reconociendo el correspondiente margen de apreciación con que al efecto ha de contar la cámara, dado que nuestro análisis no puede entrañar un juicio de intenciones políticas (SSTC 66/1985, de 23 de mayo, FJ 1, y 239/1992, de 17 de diciembre, FJ 2).

Esta disociación entre medidas necesarias y medidas proporcionadas, de difícil entendimiento desde una perspectiva estrictamente jurídica, cobra, sin embargo, sentido si la examinamos desde la autocontención que, en asunto de esta naturaleza, se espera del Tribunal. El control político también es un control constitucional. Más aun, en el caso del art. $155 \mathrm{CE}$, debiera ser el control por excelencia.

Desde esta perspectiva, el Tribunal podría haberse limitado, a mi juicio, al examen de la concurrencia del presupuesto habilitante sin entrar a fiscalizar la «necesidad» de cada concreta medida. Una cosa es precisar si las medidas propuestas son, o no, constitucionales y otra, bien distinta, examinar si, una vez acordadas por el Gobierno y el Senado, eran «necesarias» lo que, se quiera reconocer o no, conduce a un inevitable juicio de proporcionalidad más o menos encubierto.

Bastaba con controlar el presupuesto habilitante y la constitucionalidad de las medidas. No más — como, sin embargo, hizo—- pero tampoco menos ${ }^{17}$.

\section{CONTROLAR LO DECIDIDO}

Controlada la decisión y precisados sus márgenes constitucionales, existen otros muchos cauces para fiscalizar las normas y actos jurídicos derivados de aquella, algunos de los cuales pueden haber atemperado y ajustado a

7 Con todo, ha de reconocerse que el control jurisdiccional de las medidas acordadas es muy comedido y que, en muchos casos, el Tribunal orienta su razonamiento más a justificar su constitucionalidad que a motivar la necesidad de esta (véase la STC 89/2019, FF. JJ. 12 y ss.). En mi criterio, el Tribunal debe determinar si, por ejemplo, la medida de disolución de un Parlamento autonómico puede incardinarse en el elenco de «medidas» autorizadas por el art. 155 CE. Sin embargo, no creo que deba pronunciarse acerca de si, en un concreto supuesto, esa medida es necesaria o proporcionada. En mi opinión, esa decisión solo la pueden apreciar el Gobierno y el Senado y, en su caso, el control sobre su oportunidad debería ser estrictamente político. 
la realidad los términos de la medida general aprobada. Por muy constitucional y necesaria que sea una medida, no con ello se garantiza que su implementación haya sido la más adecuada o que se haya ajustado a la legalidad.

El control de los efectos derivados de las medidas de intervención acordadas por el Senado puede ser político o jurídico. El primero, como veremos, se produce en sede parlamentaria, y el segundo, al situarse en el plano de la legalidad (sujeción a un acuerdo que tiene valor de ley), corresponderá preferentemente a la jurisdicción contencioso-administrativa. Por último, debemos tener presente el control relativo a la fiscalización de las cuentas y de la gestión económica de las Administraciones y entidades integrantes del sector público, que corresponde a la jurisdicción contable y que, obviamente, no desaparece por el hecho de haberse activado el poder excepcional regulado en el art. 155 CE. Sin embargo, ni en el acuerdo del Gobierno ni en el del Senado se hace referencia alguna a este último asunto, ni se especifica si el criterio de distribución funcional de la competencia entre el Tribunal de Cuentas y la Sindicatura de Comptes de Cataluña se mantiene en iguales términos o, si por el contrario, debe experimentar algunos cambios como consecuencia de la traslatio que en el ejercicio de determinadas potestades públicas produce el acuerdo aprobado por el Senado.

Detengámonos, pues, muy brevemente, en cada uno de estos controles.

\subsection{El control parlamentario}

El acuerdo del Consejo de Ministros, en su apartado E.9, establece que el Gobierno dará cuenta al Senado del estado de aplicación y ejecución de las medidas contenidas en él con una periodicidad de dos meses. El Acuerdo del Senado, de 27 de octubre de 2017, señala: «Sin perjuicio de lo establecido en el art. 66.2 de la Constitución, las facultades de seguimiento y control de las medidas contenidas en el Acuerdo se atribuyen a la Comisión conjunta de las Comisiones General de Comunidades Autónomas y Constitucional» (apartado II.g). El cambio de orientación del precepto era inevitable. No parece razonable que el Gobierno le diga al «controlador» cómo y cuándo lo puede controlar, es decir, mediante comparecencia a petición propia y cada dos meses.

La fórmula propuesta por el Acuerdo del Senado parece mucho más adecuada a las previsiones constitucionales. Con todo, cabría preguntarse si la Mesa del Senado podría rechazar alguna iniciativa de control relativa al contenido o al modo en que se estuviese implementado alguna de las medidas autorizadas en el acuerdo de intervención, alegando que ese control corresponde 
exclusivamente a la comisión conjunta. A mi juicio, la respuesta debe ser negativa. La cláusula «sin perjuicio» que incorpora el Acuerdo del Senado nos indica que el control ejercido por la comisión conjunta es un control adicional que se añade al que de por sí pueden ejercer el Senado y el Congreso de los Diputados a través de los instrumentos reglamentariamente establecidos para el control político del Ejecutivo (preguntas, interpelaciones, solicitud de comparecencias, ya sean en Pleno o en comisión, y hasta la posibilidad de constituir, en su caso, una comisión parlamentaria de investigación). Por la misma razón, tampoco podría sostener la Mesa del Congreso de los Diputados que la competencia para el control político de las actuaciones realizadas por el Gobierno al amparo del art. $155 \mathrm{CE}$ corresponde exclusivamente al Senado, rechazando, así, cualquier iniciativa parlamentaria relacionada con las medidas del art. $155 \mathrm{CE}$.

Pese a todo, en lo que hemos podido constatar, no existieron más actos de control del Gobierno relativos a la aplicación de las medidas previstas en el Acuerdo del Senado que los llevados a cabo en la propia Cámara Alta, ante la comisión conjunta y a iniciativa del Gobierno ${ }^{18}$.

\subsection{El control jurisdiccional}

En el apartado E1 del Acuerdo del Consejo de Ministros de 21 de octubre de 2017 se dispuso:

El ejercicio de las competencias, facultades y funciones que, en virtud de lo autorizado en este Acuerdo, se atribuya a los órganos o autoridades creados o designados por el Gobierno de la Nación, se ajustará a la normativa vigente, estatal o autonómica, que en cada caso resulte de aplicación, y su revisión jurisdiccional corresponderá a los juzgados y tribunales del orden jurisdiccional contencioso administrativo, en atención al rango de los órganos o autoridades creados o designados por el Gobierno de la Nación.

Este punto fue modificado por el Senado, que le dio la siguiente redacción:

18 Más concretamente se celebraron tres comparecencias ante la comisión conjunta. Dos fueron realizadas por el entonces secretario de Estado para las Administraciones territoriales, Bermúdez de Castro, el 4 de diciembre de 2017 (Diario de Sesiones del Senado, núm. 202) y el 22 de marzo de 2018 (Diario de Sesiones del Senado, núm. 254), y la tercera de ellas por la vicepresidenta y ministra de la Presidencia, Sáenz de Santamaría, el día 18 de diciembre de 2017 (Diario de Sesiones del Senado, núm. 207). 
La revisión jurisdiccional de los actos y disposiciones dictados por sustitución en las funciones o competencias de los órganos de la Administración de la Generalitat de Cataluña se sujetará a las previsiones de la legislación procesal. La revisión jurisdiccional de los actos y disposiciones dictados en aplicación de las medidas previstas en este Acuerdo corresponderá a los juzgados y tribunales del orden jurisdiccional contencioso administrativo, en atención al rango de los órganos o autoridades creados o designados por el Gobierno de la Nación (apartado II.d del Acuerdo del Senado).

En su primera versión, y en lo que a nosotros importa, el precepto prácticamente se limitaba a recordar que los actos que, en su caso, dictasen los nuevos órganos o autoridades creados por el Gobierno ex art. $155 \mathrm{CE}$ son susceptibles de revisión jurisdiccional ante los jueces y tribunales del orden contencioso-administrativo según las reglas comunes establecidas para la determinación de la competencia en función de la naturaleza del órgano o autoridad (rango es la palabra utilizada en el texto) que lo hubiese dictado (art. 8 LJCA). Tras su paso por el Senado, como hemos visto, se introdujo una matización que oscurece un poco la claridad de este punto del acuerdo.

En efecto, la nueva redacción diferencia expresamente entre la revisión de los actos y disposiciones «dictados por sustitución» y la revisión jurisdiccional de «los actos y disposiciones dictados en aplicación de las medidas» previstas en el acuerdo. Como los primeros también son actos y disposiciones comprendidos en el segundo de los incisos, solo cabe entender que lo único que pretende la nueva versión de la norma - aunque su redactado resulte parcialmente reiterativo- es afirmar que todos los actos y disposiciones de naturaleza administrativa dictados como consecuencia de la aplicación del art. 155 CE están sujetos a la jurisdicción contencioso-administrativa, según lo previsto en la legislación procesal.

Sin embargo, esta interpretación presenta algunas dificultades prácticas. Si consideramos que los actos y disposiciones aprobados para implementar las medidas previstas en el Acuerdo del Senado son «dictados por sustitución en las funciones o competencias de los órganos de la Administración de la Generalitat de Cataluña», y a ello unimos que la competencia se determinará «en atención al rango de los órganos o autoridades creados o designados por el Gobierno de la Nación», cabe preguntarse ante qué concreto órgano de la jurisdicción contencioso-administrativa deben ser impugnados los actos y disposiciones imputables a la Administración de la Generalitat bajo la vigencia del Acuerdo del Senado. Supongamos que pretendemos recurrir una orden de un departamento de la Generalitat que está firmada (por sustitución) por el secretario de Estado o el subsecretario de un ministerio en quien se ha delegado la 
firma, ¿dónde tendríamos que interponer el recurso?, ¿ante la Sala de lo Contencioso-Administrativo del Tribunal Superior de Justicia de Cataluña o ante la de la Audiencia Nacional? La cuestión dista de ser clara y enunciados como el de la «Orden INT/1074/2017, de 7 de noviembre, sobre delegación de funciones en órganos del Departamento de Interior de la Generalitat de Cataluña, en virtud de las medidas autorizadas con fecha de 27 de octubre de 2017 por el Pleno del Senado respecto de la Generalitat de Cataluña en aplicación del artículo155 de la Constitución» (BOE, núm. 271, de 8 de noviembre de 2017, pp. 107404 a 107407) ayudan a mantener la duda. Sin tener constancia a día de hoy de la existencia de un criterio judicial sobre esta cuestión, atendiendo a la naturaleza del poder excepcional previsto en el art. $155 \mathrm{CE}$ y al hecho de que en ningún caso puede comportar una suspensión del derecho a la autonomía, lo más consecuente sería entender que, con independencia de los mecanismos de sustitución y delegación, se diese prioridad a la titularidad de la Administración de la que emana el acto o disposición como criterio de determinación de la competencia jurisdiccional.

\subsection{El control contable}

Nada dicen, ni el acuerdo del Consejo de Ministros ni el del Senado, sobre la fiscalización de la gestión económica de las autoridades gubernamentales que transitoriamente han suplido a las autonómicas bajo la vigencia de las medidas aprobadas tras la intervención amparada en el art. $155 \mathrm{CE}$. El silencio, en este punto, obliga a entender que serán de aplicación las reglas generales de distribución funcional de competencias entre el Tribunal de Cuentas y la Sindicatura de Comptes de Cataluña (SSTC 187/1988 y 18/1991, en relación esta última con el Consello de Contas de Galicia), sin olvidar que el primero es único en su orden en todo lo concerniente al enjuiciamiento contable. En suma, la activación del poder excepcional del art. $155 \mathrm{CE}$ no alteraría el reparto ordinario de tareas legalmente establecido por las leyes en el ámbito de la fiscalización de la gestión económica realizada por las respectivas Administraciones.

\section{UNA REFLEXIÓN FINAL}

El poder excepcional del art. $155 \mathrm{CE}$ está sujeto a una serie de controles políticos y jurídicos que parecen suficientes para evitar una utilización abusiva de este. Pero el éxito de esa pluralidad de cauces de control depende, en última 
instancia, de una correcta delimitación de estos. En necesario dejar que la política haga su trabajo y asuma sus responsabilidades. Y, del mismo modo, es imprescindible que el Tribunal Constitucional, los jueces y tribunales del orden contencioso-administrativo y el Tribunal de Cuentas limiten el alcance de su jurisdicción sin incurrir en tentaciones sustitutivas.

Ambos circuitos, el de la política y el del derecho, con sus motivaciones y sus particulares asignaciones de roles, están llamados a complementar el fundamento deliberativo de la democracia, evitando el abuso de poder y populismos gobernados por la emotividad. En situaciones límite, como las requeridas para activar el art. $155 \mathrm{CE}$, el acierto en esa distribución de tareas es decisivo. Los procedimientos y los controles — políticos y jurídicos-ilustran la controversia pública y suministran un aporte de legitimidad que hace posible entender que, con independencia del principio de la mayoría, los demás también tienen sus razones, aunque no convenzan ni se compartan. Sobre tan delicada telaraña se balancea el art. 155 de nuestra Constitución.

\section{Bibliografía}

Albertí Rovira, E. (2018). Cuestiones constitucionales en torno a la aplicación del art. 155 $\mathrm{CE}$ en el conflicto de Cataluña. Revista d'estudis autonòmics i federals, 27, 1-23. Disponible en: https://doi.org/10.22201/iij.24484881e.2017.36.10869.

Álvarez, L. (2016). La coerción estatal del art. 155 CE en la estructura del estado autonómico. Teoria y Realidad Constitucional, 38, 277-304. Disponible en: https://doi.org/10.5944/ trc.38.2016.18590.

Aragón Reyes, M. (1995). Constitución y control del poder. Buenos Aires: Ediciones Ciudad Argentina.

Caamaño, F. (2017). Del Estatut a las leyes de desconexión: el dedo que escribe las Tablas de la ley. En X. M. Rivera Otero (coord.). Cataluña en proceso: las elecciones autonómicas de 2015 (pp. 17-33). Valencia: Tirant lo Blanch.

Cruz Villalón, P. (1980). La protección extraordinaria del Estado. En A. Pedrieri y E. García de Enterría (dirs.). La Constitución española de 1978 (pp. 689-717). Madrid: Civitas.

García de Enterría (1983). La ejecución autonómica de la legislación del Estado. Madrid: Civitas.

García Torres, J. (1984). El artículo 155 de la Constitución espańola y el principio constitucional de autonomía. En VV. AA. Organización territorial del Estado, vol. II (pp. 11891303). Madrid: Instituto de Estudios Fiscales.

Martín i Alonso, G. (2019). Dossier sobre l'aplicació de l'article 155 CE a Catalunya. Revista Catalana de Dret Públic (número especial), 182-213.

Urías, J. (2019). El artículo 155 CE: alcance y límites de una excepción constitucional. Revista Catalana de Dret Públic (número especial), 101-114.

Vilajosana, Josep M. (2019). El Estado dual en Espańa: contexto y justificación de la aplicación del artículo 155 CE. Revista Catalana de Dret Públic (número especial), 137-155. 